\title{
Adaptive Wetting of Polydimethylsiloxane
}

\author{
William S. Y. Wong, Lukas Hauer, Abhinav Naga, Anke Kaltbeitzel, Philipp Baumli, Rüdiger Berger, \\ Maria D'Acunzi, Doris Vollmer, and Hans-Jürgen Butt*
}

Cite This: Langmuir 2020, 36, 7236-7245

Read Online

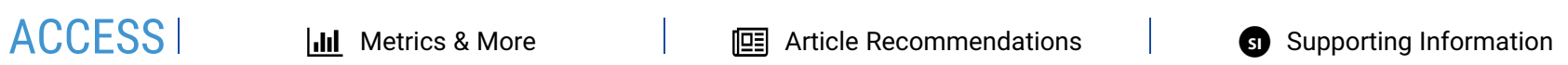

ABSTRACT: To better understand the wetting of cross-linked polydimethylsiloxane (PDMS), we measured advancing and receding contact angles of sessile water drops on cross-linked PDMS as a function of contact line velocity (up to $100 \mu \mathrm{m} / \mathrm{s}$ ). Three types of samples were investigated: pristine PDMS, PDMS where oligomers were removed by toluene treatment, and PDMS with an enriched concentration of oligomers. Depending on the velocity of advancing contact lines and the contact time with water, different modes of wetting were observed: one with a relatively low contact angle hysteresis $\left(\Delta \theta \approx 10^{\circ}\right)$ and one with a larger hysteresis. We attribute the low

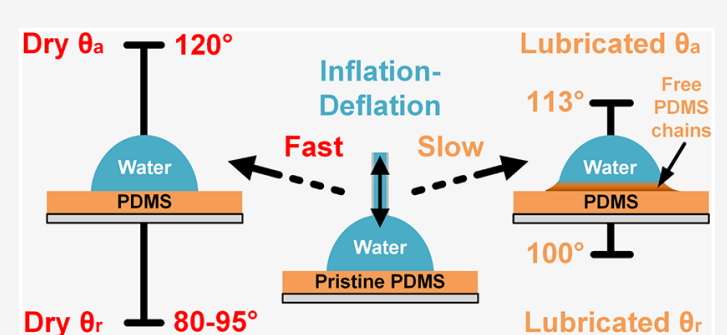
hysteresis state, called the lubricated state, to the enrichment of free oligomers at the water-PDMS interface. The enrichment of oligomers is induced by drop contact. The kinetics of the transition to the lubricated state can be described by adaptation theory. PDMS adapts to the presence of water by an enrichment of free oligomers at the interface and a correlated reduction in interfacial tension.

\section{INTRODUCTION}

The wetting of polydimethylsiloxane (PDMS) by water has been widely studied. One reason for this interest is the application of PDMS in, for example, a household sanitary environment or as an electric insulator. Although the material is hydrophobic with contact angles in the order of $90^{\circ}$, cross-linked PDMS can take up to $\approx 30 \mathrm{mM}$ water when in contact with water. Water molecules diffuse with a diffusion coefficient of $2.5 \times 10^{-9} \mathrm{~m}^{2} / \mathrm{s}$, which is of the same order of magnitude as the self-diffusion coefficient of water. ${ }^{1,2}$ Despite the fact that the wetting of PDMS has been studied intensely, reported advancing and receding contact angles vary significantly depending on the specifics of preparation, pretreatment, contact time with water, and velocity of the advancing or receding contact lines. The aim of this paper is to better understand dynamic advancing, $\theta_{a}$, and receding contact angles, $\theta_{\mathrm{r}}$, on cross-linked PDMS surfaces. How do $\theta_{\mathrm{a}}$ and $\theta_{\mathrm{r}}$ depend on the velocity of the advancing and receding contact line and how do the functions $\theta_{\mathrm{a}}(v)$ and $\theta_{\mathrm{r}}(v)$ adapt to the exposure to water?

In general, contact angles depend on how fast the contact line moves. The two most well-known descriptions of dynamic contact angles are the hydrodynamic and molecular kinetic theories. ${ }^{3-5}$ Hydrodynamic models explain the velocity dependence of the advancing contact angle by assuming that viscous dissipation caused by flow within the corner in front of the moving contact line dominates. The shear stress in the wetting ridge diverges upon approaching the contact line. This divergence can be circumvented by defining a lower cutoff length, typically of molecular size. In this microscopic regime, slip between the solid and liquid is allowed. Molecular kinetic theory (MKT) assumes that the motion of the contact line is governed by the dynamics of the molecules in the close vicinity of the three-phase contact region, that is, the region where the surface, liquid, and gas phases meet. ${ }^{3}$ The driving force for the contact line to move is an out-of-equilibrium surface tension; $\gamma_{\mathrm{LV}}\left(\cos \theta^{0}-\cos \theta\right)$ where $\gamma_{\mathrm{LV}}$ is the liquid-vapor interfacial tension, $\theta^{0}$ is the equilibrium, and $\theta$ is the dynamic contact angle. ${ }^{6}$ Thermally activated adsorption/desorption processes of the molecules occur at the advancing/receding side of a moving drop. The velocity-dependent contact angles are modeled in terms of the "jumping" distance and frequency, two parameters which depends on the system's inherent cohesive and adhesive forces. ${ }^{7}$ Both hydrodynamic and MKT models are often able to reproduce measured dynamic contact angles. ${ }^{8}$ However, the fitting parameters may not always fit realistic expectations, that is, the lower cutoff length can be far below $1 \AA$ or the jumping frequencies can be surprisingly high or low. In particular, both theories do not predict significant changes in contact angles for capillary numbers below $10^{-4} ;{ }^{6,9-11}$ and the capillary number is the velocity of the contact line $v$ multiplied with its viscosity $\eta$ and divided by the surface tension of the liquid, $\gamma: C a=\eta v / \gamma$.

Lately, another model was proposed, taking into account a wetting-induced adaptation of surface energies, so-termed adaptive wetting. ${ }^{12}$ In the case of cross-linked PDMS, there is already experimental evidence for adaptation. When PDMS is

Received: February 25, 2020

Revised: June 4, 2020

Published: June 4, 2020 
hydrophilized, for example, by exposing it to corona discharge or an oxidizing plasma, it recovers its hydrophobicity when aging in air for few hours or days. ${ }^{13}$ Aging in water does not recover hydrophobicity. ${ }^{2,14}$ This recovery is explained by the diffusion of residual silicone oligomers which are not cross-linked and which remain in the PDMS. ${ }^{15,16}$

Here, contact angles are measured optically while volumes of sessile drops were increased and decreased. The sessile drop method is the most common method to determine contact angles. As it turns out, the accessible contact line velocities are susceptible to the adaptation of cross-linked PDMS to water. Instead of well-defined dynamic advancing and receding contact angles, PDMS shows two advancing contact angle plateaus under drop inflation and a minimum receding contact angle before the plateau for drop deflation, spatially dependent on the pre-exposure to water.

\section{METHODS}

Synthesis of Test Surfaces. Three types of PDMS surfaces were studied. The PDMS was either used as prepared (pristine PDMS, still containing 4-5 wt \% free chains), "dry" (free chains were removed by washing with toluene and drying), or "lubricated" (adding $8 \mathrm{wt} \%$ free PDMS chains).

Pristine PDMS was prepared using cross-linked Sylgard 184 PDMS, mixed at a 1:10 weight ratio $(1: 10 \mathrm{~g})$ of cross-linker-to-vinyldimethylsiloxane, respectively, in a $20 \mathrm{~mL}$ vial stirred at ca. $60 \mathrm{rpm}$, for $2 \mathrm{~min}$. The base (part A) contained dimethyl siloxane, dimethylvinyl-terminated, dimethylvinylated, and trimethylated silica, tetra(trimethoxysiloxy) silane, and ethyl benzene. Volatile organic content is $8 \mathrm{~g} / \mathrm{L}$. The curing agent (part B) contained dimethyl, methylhydrogen siloxane, dimethyl siloxane, dimethylvinyl-terminated, dimethylvinylated, and trimethylated silica, tetramethyl tetravinyl cyclotetra siloxane, and ethyl benzene. This is a three-component system that includes a base, curing agent, and catalyst. The third component, which is part of the curing agent, comprises of a metalcentered catalyst that promotes cross-linking. This is a platinum complex which promotes a hydrosilylation reaction between the methylhydrogen siloxane and the terminal vinyl groups in the curing agent and the base formulation, respectively. ${ }^{17}$ Glass slides of $170 \mu \mathrm{m}$ thickness were rinsed with ethanol and exposed to an oxygen plasma (0.4 bar) for $5 \mathrm{~min}$ at $300 \mathrm{~W}$ (Femto, Diener Electronic, Germany). After spin-coating the cross-linker-vinyldimethylsiloxane mixture (1000 $\mathrm{rpm}$ for $60 \mathrm{~s}$, ramped up in $15 \mathrm{~s}$ ), samples were cured in a heated oven at $60{ }^{\circ} \mathrm{C}$ for $18 \mathrm{~h}$. The PDMS coatings had a thickness of $\approx 60 \mu \mathrm{m}$ as measured by cross-section analysis in scanning electron microscopy (SEM). The magnification error of SEM can range from 5 to $10 \%$, and this reported thickness should be taken within an order of the reported magnitude.

Dry PDMS surfaces were obtained by soaking the as-prepared pristine PDMS samples in excess toluene (1 glass slide, $2 \times 6 \mathrm{~cm}^{2}$ at 60 $\mu \mathrm{m}$ thickness in $100 \mathrm{~mL}$ of toluene) for $24 \mathrm{~h}$. Oligomers in the eluent were analyzed by chromatography, see below. The washed samples were then dried in vacuum at $1 \mathrm{mbar}$ for $72 \mathrm{~h}$. The saturation vapor pressure of toluene is $37.5 \mathrm{mbar}$, and the lower-than-saturation pressure applied for an extended time should thus be sufficient for solvent extraction. The amount of free oligomers was determined by weighing samples before and after PDMS extraction. Free oligomers were extracted from within the PDMS matrix, accounting to between 4 and $5 \%$ by weight.

Lubricated PDMS samples were prepared as pristine PDMS, except that we added $8 \mathrm{wt} \%$ unreactive PDMS oligomers $\left(M_{\mathrm{w}}=2000 \mathrm{~g} / \mathrm{mol}, \mu\right.$ $=20 \mathrm{cSt}$, methyl-terminated, Aldrich) during the blending of crosslinkers and vinyldimethylsiloxane monomers. The molar mass of oligomers added was aligned to the molecular weight of the free oligomers in pristine PDMS, as shown in Figure S1. The "dry" and "lubricated" PDMS surfaces serve as benchmarks for understanding the dry-to-lubricated adaptive nature of pristine PDMS.
Gel Permeation Chromatography. Gel permeation chromatography experiments were performed using an Agilent Technologies 1260 instrument consisting of a pump, autosampler, and column oven. As an eluent, toluene was used. A column set consisting of three columns: SDV $106 \AA$, SDV $104 \AA$, and SDV $500 \AA$ (PSS Standards Service $\mathrm{GmbH}$, Mainz, Germany), all of $300 \times 8 \mathrm{~mm}$ and $10 \mu \mathrm{m}$ average particle size was used at a flow rate of $1.0 \mathrm{~mL} / \mathrm{min}$ and a column temperature of $30^{\circ} \mathrm{C}$. The injection volume was $100 \mu \mathrm{L}$. Detection was accomplished with a refractive index detector (Agilent Technologies). In order to reproduce the measurement, each sample was injected twice. Data acquisition and evaluation was performed using PSS WINGPC UniChrom (PSS Polymer Standards Service GmbH, Mainz, Germany). Calibration was carried out using the universal calibration method with polystyrene standards provided by PSS Polymer Standards Service GmbH (Mainz, Germany) and the Mark-Houwink coefficients for PDMS in toluene.

Wetting and Contact Angle Analysis. Dynamic contact angle measurements were performed in the sessile drop configuration under variable volumetric flow rates. Fitting of dynamic contact angles and contact line displacements were performed using the automated program provided by the manufacturer: SCA20, Dataphysics. We have made use of the "Sessile Drop-Needle In Algorithm", with dynamic contact angles fitted via an ellipse. The ellipse-fitting method was chosen because of its accuracy in determining contact angles within our operating range $\left(90-120^{\circ}\right)$ and drop volume $(5-25 \mu \mathrm{L})$. All data (including controls) were analyzed using this method for consistency. Readers should be aware of potential differences in measured contact angles with the use of different fitting methods (ellipse, tangent, YoungLaplace, etc.) in order to avoid misinterpretation. ${ }^{18-21}$ To ensure defined flow rates, a custom-built nanoliter-resolution pump was specifically designed, with a range of flow rates between $50 \mathrm{~nL} / \mathrm{s}$ and 2 $\mu \mathrm{L} / \mathrm{s}$ (Methods, Supporting Information). We inserted a bent needle (fluoro-treated) from the back of the drop to minimize needle-induced asymmetric distortions of the drop shape during inflation or deflation. ${ }^{22}$ As a result, the left and right contact angles perfectly overlaid. The repeatability of the experiments was verified at least 3 times on independent experiments, with two contact angles measured during each run (6 data measurements per graph). Errors in measurements typically fall within $\pm 1^{\circ}$ and are smaller than the symbol sizes in the figures. All experiments were performed with an initial drop size of ca. $2.5 \mu \mathrm{L}$; we chose a minimal starting volume to avoid evaporation effects between drop formation and the start of drop inflation. The initial 0.5 $\mu \mathrm{L}$ needed to reach $3.0 \mu \mathrm{L}$ allows the drop to achieve its maximum dynamic advancing contact angle. Typically, we truncated all graphs from $3.0 \mu \mathrm{L}$ onwards to remove the minute differences that were induced by human inputs from 2.5 to $3.0 \mu \mathrm{L}$.

Velocity and Displacement Analysis. How is the contact line velocity related to the flow rate? As the volume of the drop was increased/decreased at a constant volumetric rate, $(\dot{V})$, the contact line velocity, $v$, was not constant. At a constant contact angle, it scales with $v$ $\propto V^{-2 / 3} \dot{V}$. When increasing/decreasing the drop volume, the contact line velocity decreases/increases (Figure S2). Deviations from this scaling are caused by changes in the contact angle. Experimentally, the velocities determined were based on actual video measurements. We are able to automatically measure the displacement of the contact line based on the videos, which can then be step-wise evaluated as velocity-volume plots. A range of absolute $v$ do exist throughout the entire inflation-deflation cycle. However, we present the average contact line velocity, $\bar{v}$ selected over both advancing and receding segments of the contact line velocity profiles. These were abstracted while considering (1) similar drop volumes, (2) excluding sharp velocity fluctuations, and (3) averages over at least a domain of $3 \mu \mathrm{L}$. The mean contact line velocity $\bar{v}$ was determined by averaging the advancing $(<500 \mathrm{~nL} / \mathrm{s})$ or receding $(\geq 500 \mathrm{~nL} / \mathrm{s})$ velocities in the velocity-volume graphs (without jumps in velocity that are induced by contact angle variations). Error bars presented in average contact line velocity represent deviations within one inflation-deflation cycle. Notably, $\bar{v}$ did not change significantly between inflation and deflation unless the contact line was temporally pinned. 

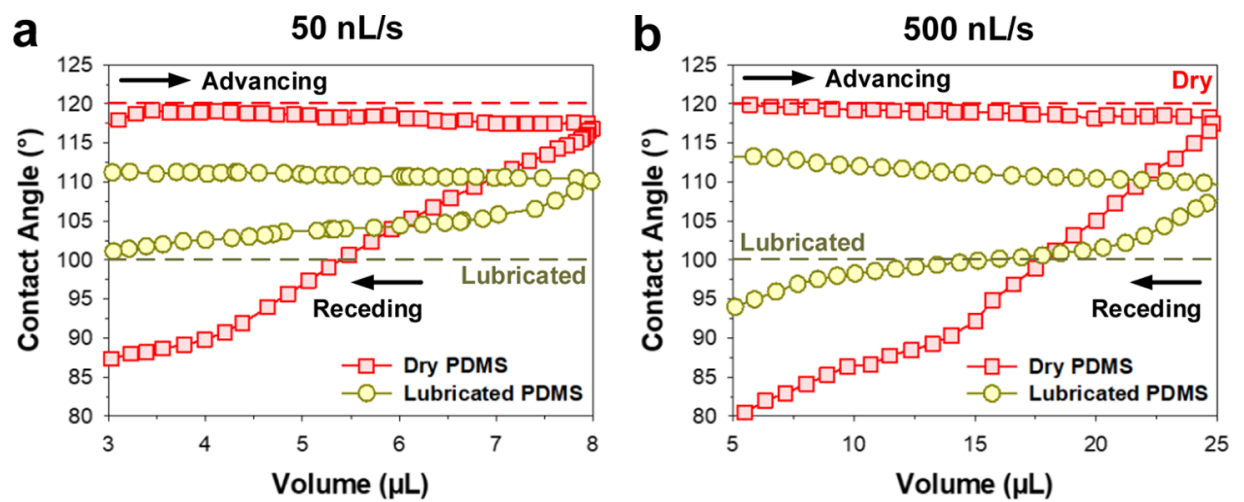

Figure 1. Contact angle of water on dry and lubricated PDMS at low and high contact line velocity. (a) Contact angles measured at low flow rates (50 $\mathrm{nL} / \mathrm{s}$ correspond to an average contact line velocity of $3-4 \mu \mathrm{m} / \mathrm{s})$. (b) Contact angles observed at high flow rates $(500 \mathrm{~nL} / \mathrm{s}$ correspond to an average contact line velocity of $30 \mu \mathrm{m} / \mathrm{s}$ ). Three separate readings were taken; only representative curves are presented for clarity. The standard errors are typically around $1^{\circ}$ between repeat experiments performed on the same day. The $60 \mu \mathrm{m}$-thick PDMS films were fabricated on $170 \mu \mathrm{m}$-thick glass cover slips.

In this work, the key variable is either more appropriately represented as velocity or displacement. A displacement analysis experiences lesser noise, but the former is integrated better into the adaptive wetting equations that we will later describe. In addition, volume, as presented remains one typical representation in these dynamic contact angle measurements. The contact angle/volume and contact angle/ velocity-displacement data will be presented in either the main manuscript or the Supporting Information. These are the experimentally accessible data sets. To convert these into an improved intuition for contact time, we convert these to contact line velocities for the evaluation of adaptive wetting.

\section{RESULTS AND DISCUSSION}

Dry and Lubricated PDMS. Dry and lubricated PDMS represent the two limiting cases. On a dry PDMS surface (Figure 1a, red squares), the advancing contact angle observed during inflation is $\theta_{\mathrm{a}}=119-120^{\circ}$ (dashed red line) at a slow volumetric inflation-deflation rate $(50 \mathrm{~nL} / \mathrm{s})$. During deflation, the contact line was pinned. As a result, the contact angle dropped continuously until a volume of $4 \mu \mathrm{L}$ was reached. After depinning, the contact angle decreased with a reduced slope and reached a value of $87^{\circ}$ at a volume of $3 \mu \mathrm{L}$. On a lubricated PDMS surface (Figure 1a, yellow circles), the contact line advanced at a lower angle $\left(\theta_{\mathrm{a}} \approx 110^{\circ}\right)$. When decreasing the volume of the water drop, the contact line first pinned. The contact angle linearly decreased until it reached $104^{\circ}$. Decreasing the volume even further, the contact line depinned and receded at a constant contact angle of $\theta_{\mathrm{r}}=104^{\circ}$ at $\approx 7.5 \mu \mathrm{L}$. Then, $\theta_{\mathrm{r}}$ only slightly decreased until it reached a value of $\theta_{\mathrm{r}}=$ $101^{\circ}$ (dashed yellow line) at a volume of $3 \mu \mathrm{L}$.

Contact angle hysteresis, $\Delta \theta=\theta_{\mathrm{a}}-\theta_{\mathrm{r}}$, on the lubricated PDMS, $\Delta \theta_{\mathrm{L}}=10 \pm 1^{\circ}$, was much lower than that on dry PDMS, $\Delta \theta_{\mathrm{D}}=32 \pm 3^{\circ}$. We attribute the reduced contact angle hysteresis to an enrichment of oligomers near the PDMS-water interface. The presence of excess liquid oligomers leads to lower contact angle hysteresis, as expected of a highly mobile liquidlike interface. ${ }^{23}$ In contrast to the lubricated state on slippery liquid-infused porous surfaces (SLIPS), ${ }^{24}$ no free layer $(>100$ $\mathrm{nm}$ ) of the lubricant exists on PDMS (Figure S3). They are primarily soft elastomeric surfaces that experience reorganization of surface chemistry (and energy) upon wetting. The reason for a slight change in the receding contact angle of lubricated PDMS is less clear and we can only speculate.

To observe dynamic changes in contact angles at higher flow rates ( 500 vs $50 \mathrm{~nL} / \mathrm{s}$ ), we needed to increase the maximum drop volume from 8 to $25 \mu \mathrm{L}$ to expand the domain of observation. On dry and lubricated PDMS (Figure 1b), the wetting behaviors were qualitatively similar to the ones observed at slower inflation-deflation rates. Dry PDMS showed an advancing plateau $\theta_{\mathrm{a}}$ of $119-120^{\circ}$ (dashed red line). While deflating, the contact angle decreased linearly until the contact line depinned at $V=15 \mu \mathrm{L}, \theta_{\mathrm{r}}=90^{\circ}$. Continuing to decrease the volume resulted in a further decrease in the contact angle, although with a lower slope. On lubricated PDMS, the advancing contact angle $\theta_{\mathrm{a}}$ slightly decreased from 112 to $110^{\circ}$ when increasing the volume to $25 \mu \mathrm{L}$. Then, the contact line was pinned until the volume was decreased to $\approx 20 \mu \mathrm{L}$. Between 20 and $10 \mu \mathrm{L}$, the receding angle was $\theta_{\mathrm{r}} \approx 100^{\circ}$ (dashed yellow line). Again, contact angle hysteresis was greatly reduced on lubricated PDMS, indicative of the presence of a mobile liquid-like interface. Thus, advancing and receding contact angles on dry PDMS are qualitatively similar irrespective of contact line velocity. The same holds for lubricated PDMS.

Pristine PDMS. At a low inflation rate $(50 \mathrm{~nL} / \mathrm{s})$, the contact line begins to advance at an angle $\theta_{\mathrm{a}}=119^{\circ}$ (Figure 2a). However, it decreased to $\theta_{\mathrm{a}}=113^{\circ}$ when the drop volume exceeded $4 \mu \mathrm{L}$ and stayed almost constant up to the maximum volume of $8 \mu \mathrm{L}$. The transition between both plateaus was accompanied by a non-monotonous change in the contact line velocity (Figures S4 and 2c,e). The contact line velocity increased from approximately 4 to $6 \mu \mathrm{m} / \mathrm{s}$ during the transition followed by a decrease to $3.2 \pm 0.4 \mu \mathrm{m} / \mathrm{s}$. The presence of the transition does not depend on the initial drop size.

We interpret the changes in $\theta_{\mathrm{a}}$ from 119 to $113^{\circ}$ by the reorganization and migration of oligomers from the pristine PDMS matrix to the solid-liquid interface. Notably, pristine PDMS contains a significant concentration of free oligomers (measured here at $4-5 \%$ by weight), in agreement with previous investigations. $^{25,26}$ Upon wetting of PDMS with water, the interface adapts from a dry to a lubricated state. This is evident from the decreasing contact angle hysteresis after the transitions, which hints of liquid-like surface lubrication (Figure 1). During wetting adaptation, the migration of oligomers is sufficiently fast to influence the contact line during its advancing motion. Thus, the moving contact line first interacts with a "dry state" before later interacting with a "lubricated state".

This "lubricated state" persists throughout the receding halfcycle. After expanding the drop to $8 \mu \mathrm{L}$, the volume was decreased at the same rate of $50 \mathrm{~nL} / \mathrm{s}$. The linear decrease in the 
a

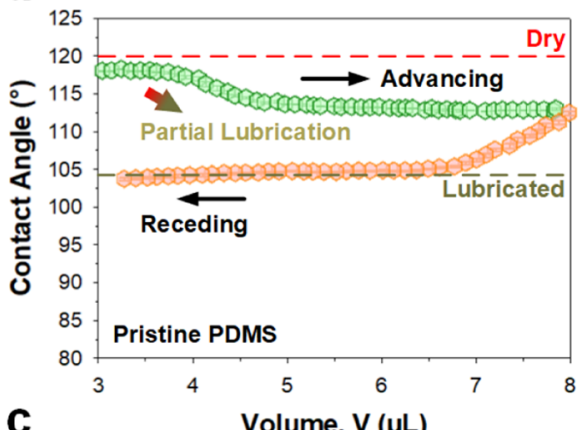

C

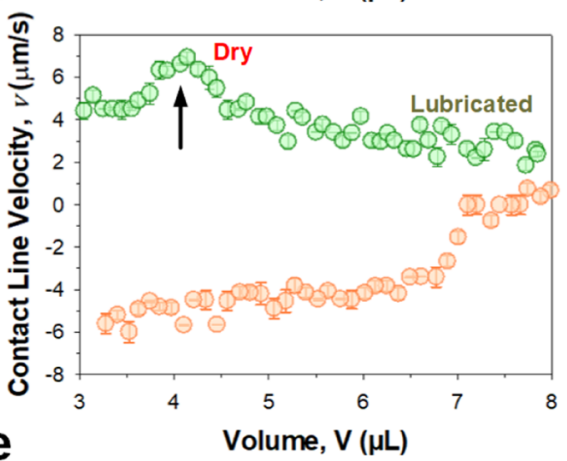

e

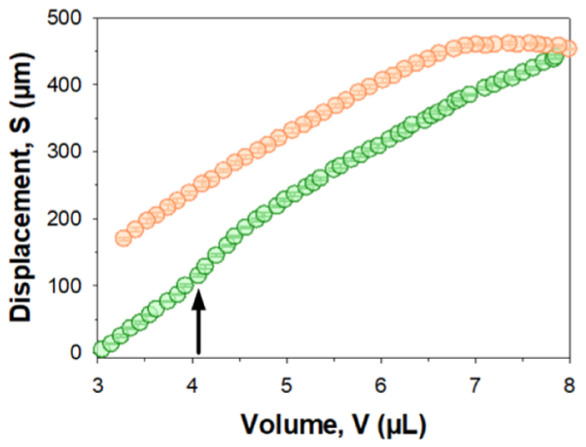

b

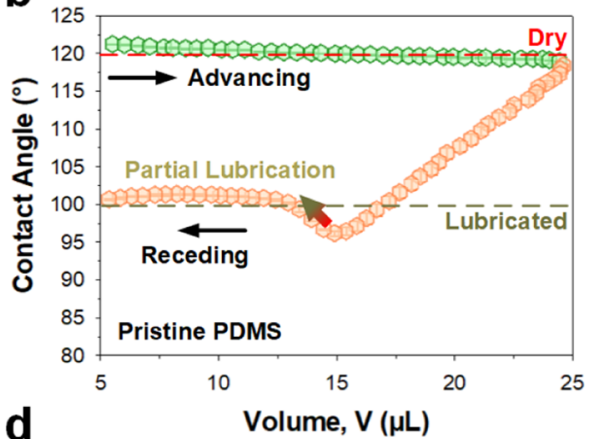

d
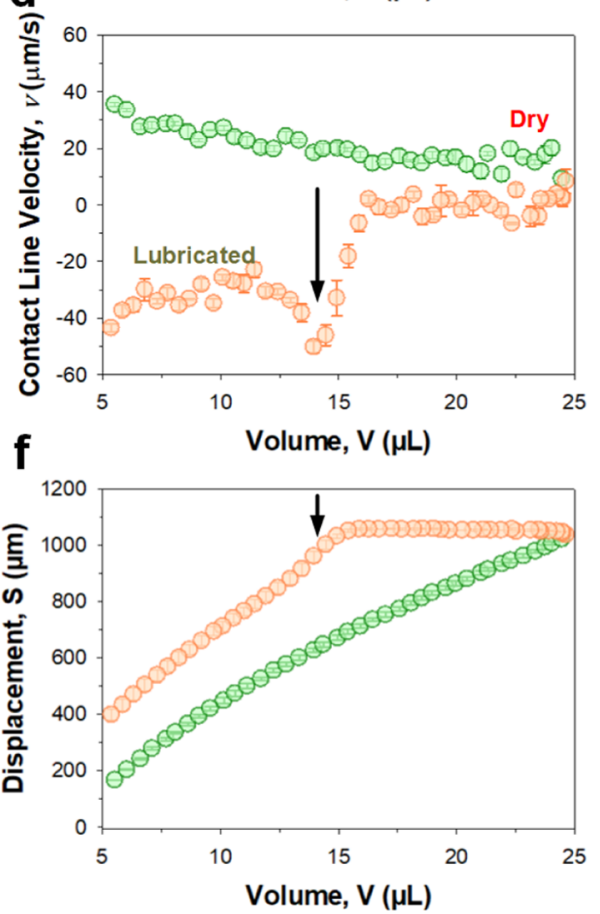
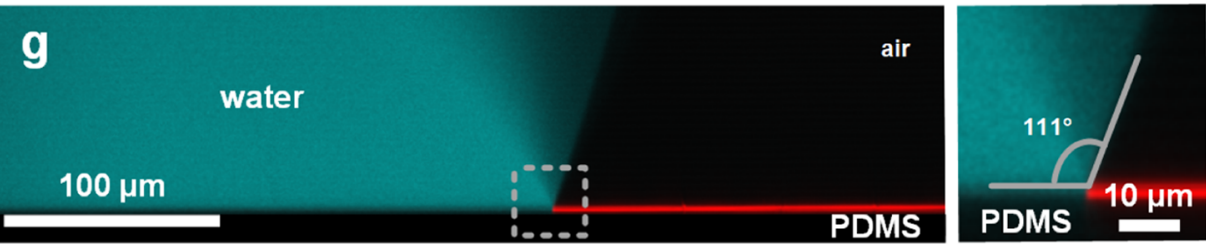

Figure 2. Contact angle of water on pristine PDMS at low and high contact line velocity. (a) Contact angle measured for a low flow rate (50 $\mathrm{nL} / \mathrm{s}$, corresponding to an average contact line velocity of $4 \mu \mathrm{m} / \mathrm{s})$. (b) Contact angles measured at high flow rates $(500 \mathrm{~nL} / \mathrm{s}$, average contact line velocity of $30 \mu \mathrm{m} / \mathrm{s}$ ). Although the advancing contact angles almost remain constant, the receding angles pass through a minimum. (c,d) Contact line velocities during drop inflation-deflation experiments for flow rates of 50 and $500 \mathrm{~nL} / \mathrm{s}$, respectively. These contact line velocities are derivatives of the videocaptured contact line displacements, which were recorded at low (e) $50 \mathrm{~nL} / \mathrm{s}$ and high (f) $500 \mathrm{~nL} / \mathrm{s}$ flow rates of drop inflation (green) and deflation (orange) respectively. Green symbols-advancing half-cycle. Orange symbols-receding half-cycle. (g) Confocal microscopy image (XZ plane) of a liquid drop of water, cyan (dyed with ATTO 488, $10 \mu \mathrm{g} / \mathrm{mL}$ ) on PDMS with a magnified inset. The reflection signal is colored in red.

contact angle before reaching a volume of $6.6 \mu \mathrm{L}$ was due to contact line pinning (Movie M1). The contact line then started to move at an almost constant contact angle of $105^{\circ}$. Such a high receding contact angle is interpreted as the presence of a "lubricated state" (Figure 1). This hints that the PDMS surface dynamically adapts to the presence of the water drop. This adaptation accounts for the transition between a higher dry $\theta_{\mathrm{a}}$ of $119-120^{\circ}$ to a lower lubricated $\theta_{\mathrm{a}}$ of $113^{\circ}$, as observed in Figure 2a,c,e. Thereafter, the drop recedes on the lubricated state.

Pristine PDMS shows a different behavior at a high inflation rate $(500 \mathrm{~nL} / \mathrm{s})$, corresponding to high mean contact line velocity $(\bar{v}=30 \mu \mathrm{m} / \mathrm{s})$. Throughout the entire advancing halfcycle, $\theta_{\mathrm{a}}$ remained high at $119-120^{\circ}$ (Figure $2 \mathrm{~b}, \mathrm{~d}, \mathrm{f}$ ), similar to the dry state, as shown in Figure 1. During the receding halfcycle, the contact angles resemble those of water in contact with dry PDMS until a volume of $15 \mu \mathrm{L}$, reaching a minimum contact angle of $95^{\circ}$. This was followed by an increase in receded $\theta_{\mathrm{r}}$ that plateaus at $100^{\circ}$, akin to lubricated PDMS, as shown in Figure 1. This close matching of the respective contact angles for pristine PDMS (Figure 2) with those of dry PDMS (Figure 1) hints that the surface remained in its dry state during the entire advancing phase and during the initial receding phase. After the drop 
volume decreased below $15 \mu \mathrm{L}$, the drop experienced a lubricated surface. Despite the evidence of the so-termed "lubrication", these surfaces should not be confused with standard SLIPS as no visible wetting ridges (up to $1 \mu \mathrm{m}$ in resolution) can be discerned (Figure $2 \mathrm{~g}$ ).

At high deflation rates, depinning is characteristically accompanied by a peak in the contact line velocity (Figure $2 \mathrm{~d}$ ) caused by pinning. The peak increases with the flow rate, most likely because of the reduced time allowed for adaptation and transition to the lubricated state. Thus, pristine PDMS displays both wetting states within a single measurement cycle. In summary, for low inflation rates (Figure 2a,c,e), a sufficient amount of oligomers migrates toward the PDMS-water interface during drop inflation, which leads to lubrication during the advancing half-cycle (starting at $\approx 4.5 \mu \mathrm{L}$ ). For high flow rates (Figure $2 \mathrm{~b}, \mathrm{~d}, \mathrm{f}$ ), the contact line advances and recedes quickly $(\bar{v}=30 \mu \mathrm{m} / \mathrm{s})$, which leads to lubrication only during the receding half-cycle (starting at $15 \mu \mathrm{L}$ ). The occurrence of lubrication is time- and contact-dependent. Therefore, depending on the relative contact line velocity, the lubrication transition can occur within either the advancing/receding cycle. Therefore, we have a dry state with $\theta_{\mathrm{a}}=120^{\circ}$ and $\theta_{\mathrm{r}} \leq 95^{\circ}$ and a lubricated state with $\theta_{\mathrm{a}}=113^{\circ}$ and $\theta_{\mathrm{r}} \approx 100^{\circ}$ (Figure 3).

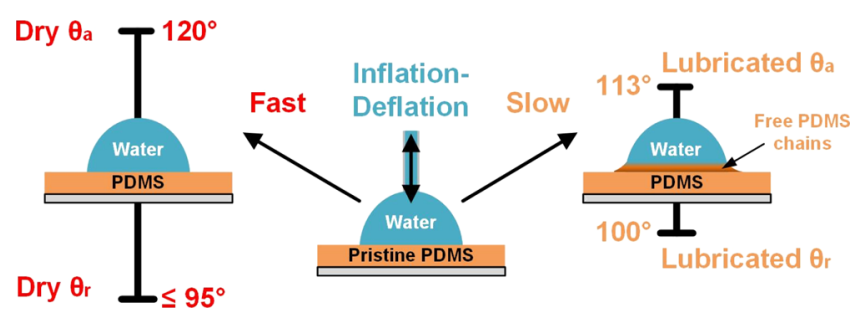

Figure 3. Sketch of dependence of the contact angle of pristine PDMS on the inflation-deflation rate. At high inflation-deflation rates $(>500$ $\mathrm{nL} / \mathrm{s}$ ), the advancing $\left(\theta_{\mathrm{a}}\right) /$ receding $\left(\theta_{\mathrm{r}}\right)$ contact angles resemble those on PDMS not containing free oligomers (dry). At low inflation-deflation rates, the advancing/receding contact angles resemble those on lubricated PDMS (free PDMS chains are not to scale).

In the PDMS represented in Figure 3, we schematized the lubricated state (not to scale). PDMS represents an organogel that is partially infused with oligomers, albeit at low concentration. The concentration of the oligomers in the pristine state is homogeneous but can be enriched at the interface during wetting.

Conditions for Adaptation-Induced Lubrication. In the following, we focus on pristine PDMS surfaces in order to provide a deeper insight toward their nature of adaptation. By increasing the flow rate from 50 to $200 \mathrm{~nL} / \mathrm{s}$, the average contact line velocity increased from $\bar{v}=4 \pm 1$ to $\bar{v}=14 \pm 2 \mu \mathrm{m} / \mathrm{s}$ (Figures 4a,b and S4). In all cases, an initial wetting plateau occurred at $\approx 119-120^{\circ}$. Then, the advancing contact angle decreased to a value of $\approx 114^{\circ}$, corresponding to the lubricated state. The end of the plateau is shifted to larger volumes with increasing flow rates. For a flow rate of $200 \mathrm{~nL} / \mathrm{s}$, this shift occurs at above $8 \mu \mathrm{L}$. At initial contact line velocities of $\gg 10 \mu \mathrm{m} / \mathrm{s}$, the contact line seems to advance faster than the rate at which the lubrication layer forms (Figure S4). Here, the contact line advances only over the dry state. The receding contact angle plateaued between $104^{\circ}(50 \mathrm{~nL} / \mathrm{s})$ and $102^{\circ}(200 \mathrm{~nL} / \mathrm{s})$. Thus, before the contact line recedes, the surface is able to adapt. This adaptation allows the contact line to recede through the lubricated state with a $\theta_{\text {r }}$ plateau at $\approx 103^{\circ}$.
When we further increased the flow rate from 150 to $300 \mathrm{~nL} / \mathrm{s}$ (and the observable drop volume to $25 \mu \mathrm{L}$ ), corresponding to $\bar{v}$ $=11 \pm 1$ to $15 \pm 3 \mu \mathrm{m} / \mathrm{s}$, the transition to the lubricated state in the advancing half-cycle is shifted to higher volumes (Figure 4c, green squares and orange hexagons). We propose that, at higher inflation rates of $500 \mathrm{~nL} / \mathrm{s}$ and higher, the contact line advances faster than the rate at which the lubrication layer can form.

The hypothesis is further supported by the observation that at even higher contact line velocities (Figure $4 \mathrm{~d}, 500 \mathrm{~nL} / \mathrm{s}, \bar{v}>20$ $\mu \mathrm{m} / \mathrm{s}$ ), no lubricated state was detected anymore during contact line advancement (Figures $4 \mathrm{~d}$ and S5). In fact, the surface does not completely adapt before commencing the receding halfcycle. Therefore, the drop begins to recede within its dry state. In contrast to flow rates up to $300 \mathrm{~nL} / \mathrm{s}$, where contact lines receded at contact angles of $101-104^{\circ}(V=5 \mu \mathrm{L})$ in the lubricated state, the receding contact angle was initially pinned (Figure 4c). The pinning delay is characteristic of a dry state interaction. Only after reaching a drop volume of $15 \mu \mathrm{L}$, at approximately $30-35 \mathrm{~s}$ of contact exposure and a contact angle of $95^{\circ}$, did the contact line depin. The receding half-cycle then continues in the lubricated state. $\theta_{\mathrm{r}}$ rises and plateaus at $100^{\circ}$. This minimum in the receding contact angle persists throughout further increments in volumetric flow rates and contact line velocities (Figures $4 \mathrm{~d}$ and S5). We confirmed this by varying $\dot{V}$ between 500 and $2000 \mathrm{~nL} / \mathrm{s}$ for maximum drop volumes of 25 $\mu \mathrm{L}$. When increasing the flow rate further, the receding contact angle follows the "dry" graph (Figure 1) to even lower drop volumes (Figure $4 \mathrm{~d}$ ) before the contact line started to move. For $\dot{V}=2000 \mathrm{~nL} / \mathrm{s}$, the minimum of $\theta_{\mathrm{r}}=85^{\circ}$ was reached at a volume as low as $10 \mu \mathrm{L}$. A continuously decreasing minimum was observed before finally rising to form the stable, lubricated $100^{\circ}$ plateau (Figure $4 \mathrm{~d}$ ). This transition was accompanied by an increase in contact line velocity (Figures S5 and S6, Movie M2).

At our maximum inflation-deflation rate of $2000 \mathrm{~nL} / \mathrm{s}$, a second effect was observed: the receding contact angle increased from a final $97-101^{\circ}$ in the last stages of deflation between $V=7$ and $5 \mu \mathrm{L}$. This phenomenon was observed in all experiments, also on both sides of the symmetrical drop. We speculate that the flow rate is so high that the retracted drop still experiences elastic stress on its PDMS-water interface after the rapid retraction (almost $300 \mu \mathrm{m} / \mathrm{s}$, Figure S5). At this point, we would like to mention that the motion observed here is different to the stickslip motion observed on very soft PDMS (static shear modulus $G=265 \mathrm{~Pa}^{27}$ vs $0.62 \mathrm{MPa}$ here) before. $^{28}$

Prewetting and Formation of the Lubrication Layer. This velocity-dependent change in contact angle raises two questions: do oligomers cloak the water drop and reduce surface tension of water? Does the enrichment of free oligomers (lubricant) at the water-PDMS interface change the interfacial tension?

Three experiments were carried out to elucidate the presence of free PDMS at the water-air and the water-PDMS interface.

- To find out if oligomers adsorb to the water-air interface and reduce the surface tension of water, inflation-deflation cycles were measured with a single drop and reused and redeposited (up to $8 \mu \mathrm{L}$ ) over three separate spots on a pristine PDMS surface (Figure 5a). The measurements fall on top of each other. Throughout all three cycles, the dry $\left(119^{\circ}\right.$, dashed red line $)$ and lubricated $\left(113^{\circ}\right)$ states were present. Thus, no surface-active substance cloaks the test drop. 

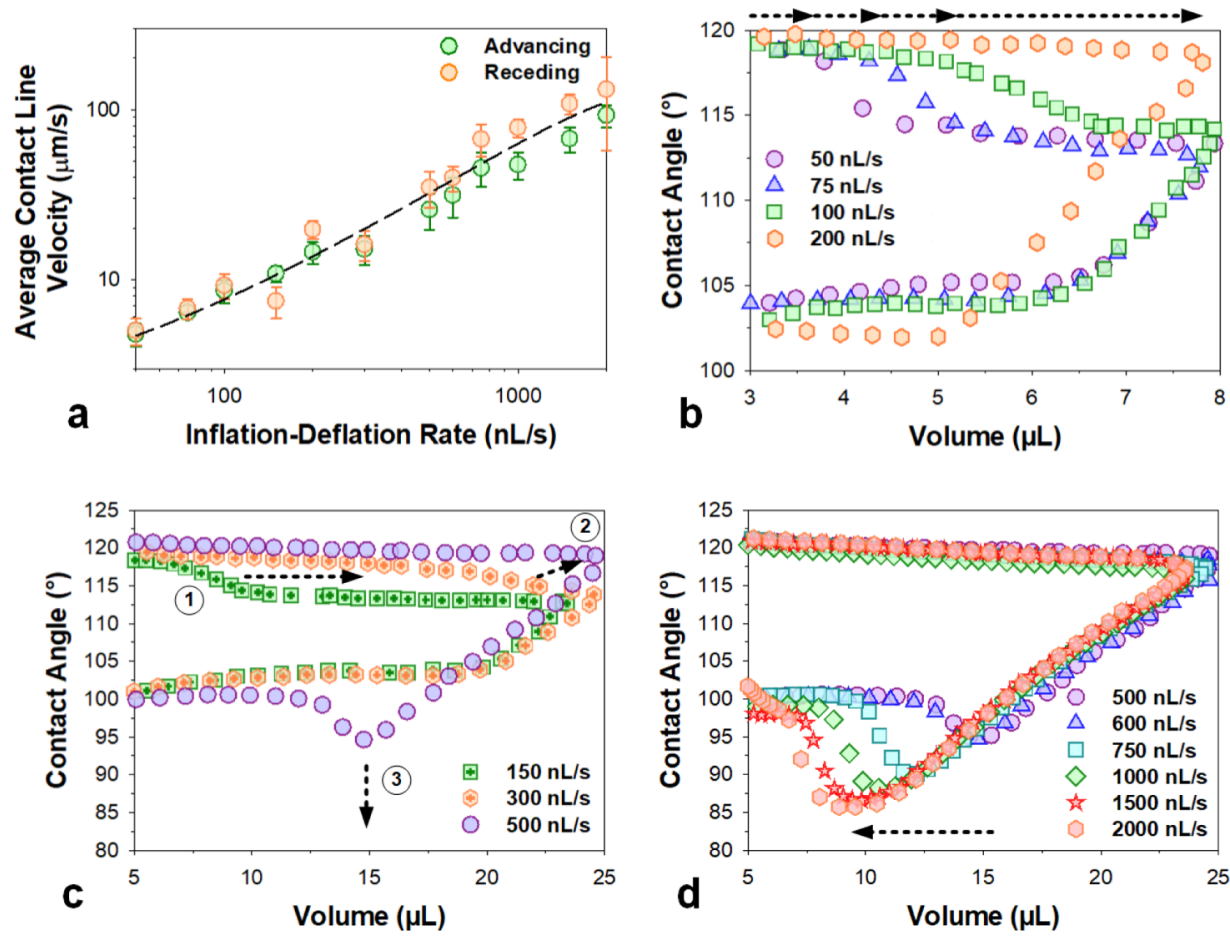

Figure 4. Influence of contact line velocity (inflation-deflation rate) on dynamic wetting. (a) Inflation-deflation rate $\dot{V}$ was used to directly control contact line velocity of the moving drop. The dashed line serves as a guide to the eye. (b) Contact angles measured at flow rates of 50,75, 100, and 200 $\mathrm{nL} / \mathrm{s}$. (c) Increasing the maximum drop volume to $25 \mu \mathrm{L}$ enabled observation of the spatial transitions within the advancing half-cycle up to a flow rate of $300 \mathrm{~nL} / \mathrm{s}$. A receding peak appeared at $500 \mathrm{~nL} / \mathrm{s}$. (d) At 500, 1000, 1500, and $2000 \mathrm{~nL} / \mathrm{s}$, the receding peak occurred at receded drop volumes of 15 , 12,10 , and $8 \mu \mathrm{L}$, respectively.

- To gain further insight into the formation and decay of the lubricated state, we placed fresh water drops on a specific spot on pristine PDMS (Figure 5b). The first inflation-deflation cycle revealed the normal dry-tolubricated transition (Figure $5 b$, red circles). Then, the drop was removed. A second fresh drop was placed at the same spot after $5 \mathrm{~min}$. The second cycle only showed the lubricated plateau (Figure 5b, yellow triangles). The presence of the water drop enriches oligomers at the interface during contact. ${ }^{24,29,30}$ This lubrication layer does not depart with the water drop during deflation. When, however, waiting for $120 \mathrm{~min}$ before placing the next drop, a third cycle demonstrated full dry-to-lubricated transition and a recovered dry state (Figure $5 b$, orange squares). This indicates that oligomers slowly diffuse back into the polymer matrix when exposed to an ambient environment, thus going back to the dry state.

- This result was verified using a modified pendant drop measurement. A drop of water $(30 \mu \mathrm{L})$ was deposited upside down on a pristine PDMS surface. The drop shape, hence surface tension, was continuously measured for 10 min and the shape was evaluated using the Laplace equation. The surface tension did not change from its initial $72-73 \mathrm{mN} / \mathrm{m}$ (Figure $5 \mathrm{c}, \mathrm{d}$ ) over this entire duration.

Why does the presence of water enrich oligomers at the solid-liquid interface? The migration of oligomers toward the water-PDMS interface can arise because of two effects. First, a mechanical stress is exerted at the contact line balancing the surface tension of the liquid, inducing an effective underpressure $^{31}$ and sucking up oligomers. Second, it is energetically favorable for oligomers to enrich at the water-PDMS interface.
The first is a contact line effect while the second is a contact area effect.

For the contact line effect, forces exerted by the liquid contact line on the solid have a normal component of $\gamma_{\mathrm{LV}} \sin \theta^{0}$, where $\theta^{0}$ is the actual contact angle. For a $\theta^{0}$ of $90^{\circ}$, this represents a force per unit line of $72-73 \mathrm{mN} / \mathrm{m}^{32}$ Assuming that the force is distributed over an effective width of $10 \mathrm{~nm},{ }^{33}$ the force per unit area exerted on PDMS underneath is 7.2 MPa. As the contact line moves over PDMS, it is hypothesized to pull out oligomers during travel. As a first approximation, the amount of liquid oligomers extracted from the PDMS matrix at a given position is inversely proportional to the contact line velocity.

One key explanation for the decreasing advancing contact angle upon adaptation is a spontaneous enrichment of oligomers at the water-PDMS interface. Such an enrichment is likely, considering that unreacted end groups of pristine PDMS are composed of asymmetrical $\mathrm{C}=\mathrm{C}$ bonds with $\mathrm{CH}_{2}$ tails. Such differently terminated PDMS oligomers of varying chain lengths may possess different effective surface energies under specific orientation. ${ }^{34}$ Shorter chain lengths also experience greater influence from terminal groups. Thus, if oligomers saturate at the interface, they can form a PDMS surface with lower interfacial tension $\left(\gamma_{S L}^{\text {lub }}\right)$ during wetting-induced lubrication. During this reversible enrichment process (also termed adaptation), we observe two distinct time scales: (1) adaptation time and (2) relaxation time. The relaxation time needed for returning to its original pristine state far exceeds the adaptation time (typically by 2 orders of magnitude). The coexistence of two time scales hints strongly at the occurrence of adaptation instead of mechanically driven viscoelastic dissipation which is governed by only one response time. ${ }^{35}$ Essentially, these observations cannot be explained by viscoelastic energy 

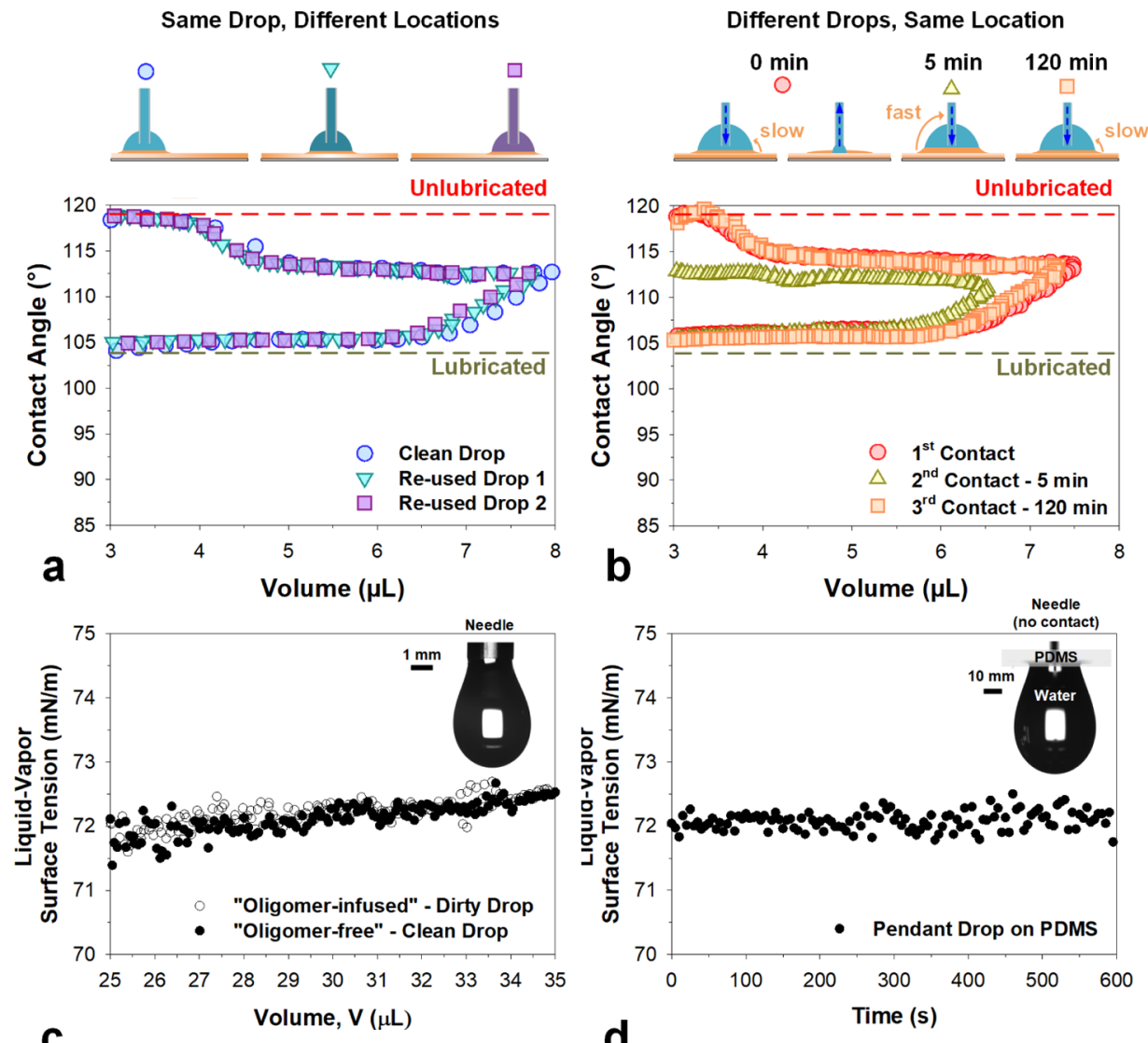

Figure 5. Lubrication layer formation on pristine PDMS. (a) Repeated use of a single drop over 3 cycles on fresh locations (circle, triangle, and square) results in identical values for the contact angle during inflation and deflation. Flow rate: $50 \mathrm{~nL} / \mathrm{s}$. (b) Water was inflated and successively deflated at an identical drop location. Time between measurements: $5 \mathrm{~min}$ between the first (circles) and second (triangle) measurement. The time between the second and third (square) measurement is $120 \mathrm{~min}$. Flow rate: $50 \mathrm{~nL} / \mathrm{s}$. The maximal volume decrease in the second cycle is attributed to evaporation losses $(1-2 \mu \mathrm{L})$ during the waiting time $(5 \mathrm{~min})$. The time between the second and third (square) measurement is $120 \mathrm{~min}$. Flow rate: $50 \mathrm{~nL} / \mathrm{s}$. The first and third cycles are aligned for representation. (c) Pendant drop of water was first tested up to $35 \mu \mathrm{L}$ (oligomer-free, clean) using the dynamic surface tension measurement technique. The same drop was deposited onto a PDMS surface for 2 min before being remeasured (oligomer-infused, dirty). (d) Alternate dynamic measurement of a pendant drop (directly on PDMS) was used to gauge if surface tension changes over a period of 10 min. Drops in $(\mathrm{a}, \mathrm{b})$ were removed and deposited using a hydrophobized needle nozzle. No sliding of the drop on the substrate took place. Every drop was cleanly (macroscopically) removed from the test surface between measurements. In $(c, d)$, the drops were kept on the surfaces throughout the experiment.

dissipation in PDMS alone because the viscoelastic properties of PDMS do not depend on the presence of water.

Wetting Adaptation Theory. To check whether dynamic contact angles can be described by the adaptive wetting model, data obtained from instantaneous velocity and dynamic advancing contact angles were fitted. ${ }^{12}$ The adaptation model is based on the assumption that surfaces spontaneously change their material properties under the presence of wetting liquids, ${ }^{4,6,8,36,37}$ giving rise to variations in interfacial tensions. These changes in interfacial chemistry influence the dynamics of contact lines and thus the dependence of the contact angles on velocity. As a first approach, wetting adaptation can be treated by first-order kinetics: $\gamma_{i}(t)=\gamma_{i}^{\infty}+\Delta \gamma_{i} \mathrm{e}^{-t / \tau_{i}} \cdot \gamma_{i}$ stands for the respective liquid-solid $\gamma_{\mathrm{LS}}$, solid-vapor $\gamma_{\mathrm{SV}}$, and liquid-air $\gamma_{\mathrm{L}}$ interfacial tension. ${ }^{12} \tau_{i}$ is the characteristic relaxation time of the adaptive process. This implies exponentially relaxing interfacial tensions. ${ }^{12}$ Implementing the adapted interfacial tensions into Young's equation $\gamma_{\mathrm{LV}} \cos \theta=\gamma_{\mathrm{SV}}-\gamma_{\mathrm{SL}}$ gives rise to velocitydependent advancing $\left(\theta_{\mathrm{a}}\right)$ and receding contact angles $\left(\theta_{\mathrm{r}}\right)$.

We fitted our entire data set of advancing contact angles versus contact line velocities. Advancing $\left(\theta_{\mathrm{a}}\right)$ contact angles and the corresponding instantaneous contact line velocities $\left(v_{\mathrm{a}}\right)$ were determined from dynamic wetting experiments. From the advancing curves, local contact line velocities were taken from the entire contact angle domain (plateaus and transitions). The experimental data set consists of $\theta_{\mathrm{a}}$ from $110-123^{\circ}$ and the respective instantaneous advancing velocities $v_{\mathrm{a}}$ of $3-100 \mu \mathrm{m} / \mathrm{s}$ (Figure 6).

When water is in contact with PDMS, the instantaneous interfacial tension is denoted by $\gamma_{\mathrm{SL}}(t)$. We assume that water contact enriches oligomers at the interface, thus decreasing interfacial tension to a new equilibrium value $\gamma_{S \mathrm{SL}}^{\infty}$. Assuming firstorder kinetics, this relaxation can be described by

$$
\gamma_{\mathrm{SL}}(t)=\gamma_{\mathrm{SL}}^{\infty}-\Delta \gamma_{\mathrm{SL}} \mathrm{e}^{-t / \tau_{\mathrm{SL}}}
$$

Here, $\tau_{\mathrm{SL}}$ characterizes the adaptation time for the enrichment of oligomers at the interface. $\Delta \gamma_{\mathrm{SL}}=\gamma_{\mathrm{SL}}^{0}-\gamma_{\mathrm{SL}}^{\infty}$ is the change in the solid-liquid interfacial energy. In the case of wetting-induced lubrication, it can also be represented as $\Delta \gamma_{\mathrm{SL}}=\gamma_{\mathrm{SL}}^{\mathrm{dry}}-\gamma_{\mathrm{SL}}^{\mathrm{lub}}$. The force balance leading to Young's equation is relevant only for a width $l_{\mathrm{SL}}$ around the contact line (also called peripheral length). Thus, the relevant interfacial tension can be expressed as 


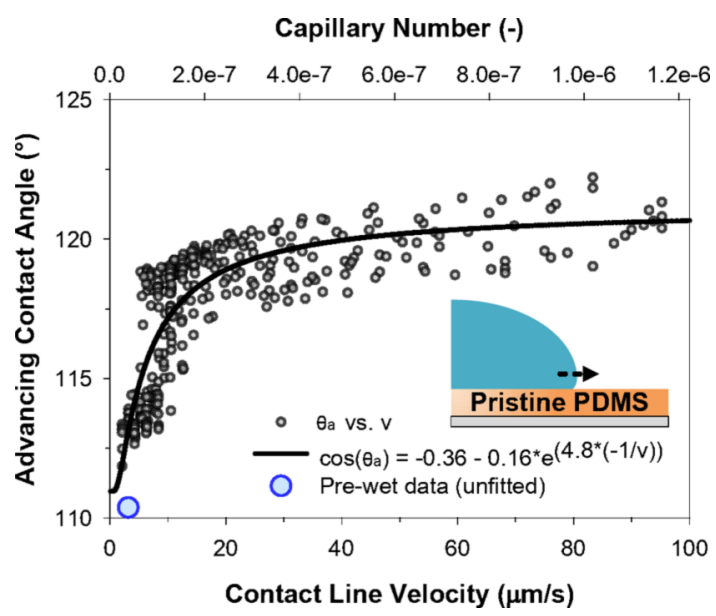

Figure 6. Advancing contact angle vs. mean contact line velocity measured for water on pristine PDMS. Experimental contact angles (symbols) were fitted with eq 4 . An experiment involving a prewetted spot (unfitted) is highlighted as a blue, marked data point for reference. Fits were achieved using all measured contact line velocities and contact angles collated from experimental data. The advancing adaptation velocity, $v_{\mathrm{SL}}$ is $4.7 \mu \mathrm{m} / \mathrm{s}$. For reference, the capillary number has been included in the alternate $x$-axis.

$$
\gamma_{\mathrm{SL}}(t)=\gamma_{\mathrm{SL}}^{\infty}+\Delta \gamma_{\mathrm{SL}} \mathrm{e}^{-v_{\mathrm{SL}} / v}
$$

Here, $v$ is the actual contact line velocity while $v_{\mathrm{SL}}=l_{\mathrm{SL}} / \tau_{\mathrm{SL}}$ characterizes the adaptation velocity of the solid-liquid interface. The characteristic adaptation velocity, $v_{\mathrm{SL}}$, represents the critical contact line velocity needed for transitioning from the dry to lubricated states. During infinitely slow steady-state advancement of the contact line, Young's equation is

$$
\gamma_{\mathrm{LV}}^{\infty} \cos \theta_{\mathrm{a}}^{\infty}=\gamma_{\mathrm{SV}}^{\infty}-\gamma_{\mathrm{SL}}^{\infty}
$$

To consider adaptation, we replace $\gamma_{S L}^{\infty}$ by the actual interfacial tension given by expression 2 . This leads to an expression for the velocity-dependent advancing contact angle $\theta_{\mathrm{a}}$

$$
\cos \theta_{\mathrm{a}}=\cos \theta_{\mathrm{a}}^{\infty}-\frac{\Delta \gamma_{\mathrm{SL}}}{\gamma_{\mathrm{LV}}^{\infty}} \mathrm{e}^{-v_{\mathrm{SL}} / v}
$$

Experimental advancing contact angles could be fitted with eq 4, as outlined in Figure 6. We fitted eq 4, assuming that $\theta_{\mathrm{a}}^{\infty}=$ $110^{\circ}$, that is, $\cos \theta_{\mathrm{a}}^{\infty}=-0.36$. Both data sets containing averaged and instantaneous contact line velocities were analyzed. For the interfacial tension of water, we used $\gamma_{\mathrm{LV}}^{\infty}$ as $72 \mathrm{mN} / \mathrm{m}$. This allows us to obtain the adaptation velocity $v_{\mathrm{SL}}=4.7 \mu \mathrm{m} / \mathrm{s}$ and the adaptation-induced change in the PDMS-water interfacial tension, $\Delta \gamma_{\mathrm{SL}}=+11.5 \pm 1.0 \mathrm{mN} / \mathrm{m}$. The obtained adaptation velocity is close to what we estimated from the contact line velocities at low inflation velocities, as shown in Figure 2. If the contact line velocity is significantly faster than $4.7 \mu \mathrm{m} / \mathrm{s}(\geq 200$ $\mathrm{nL} / \mathrm{s}$ at $>10 \mu \mathrm{m} / \mathrm{s})$, adaptation is too slow and the contact line advances in its unadapted state. An adaptation velocity of 4.7 $\mu \mathrm{m} / \mathrm{s}$ corresponds to an adaptation time of $\tau_{\mathrm{SL}}=2.1 \mathrm{~ms}$, assuming an adaptation length of $l_{\mathrm{SL}}=10 \mathrm{~nm}$. Assuming an adaptation length of $l_{\mathrm{SL}}=100 \mathrm{~nm}$ leads to an adaptation time of $\tau_{\mathrm{SL}}=21 \mathrm{~ms}$. It could be speculated whether diffusion of water into the PDMS bulk causes wetting adaptation. However, the fast diffusion of water in PDMS, $2 \times 10^{-9} \mathrm{~m} / \mathrm{s}^{2}$, should result in adaptation times within a few nanoseconds, that is, several orders of magnitude faster than what is observed experimentally. The value of the adaptation velocity may thus depend sensitively on the concentration and size of remaining oligomers in the PDMS matrix. Thus, it is likely dependent on the preparation and exposure history of the sample.

In the adaptation model, contact with a wetting drop induces exponential relaxation of interfacial tension (solid-liquid). During receding, we should have an analogous effect. The "solid" adaptation velocity $v_{\mathrm{S}}$ may be different from the "solid-liquid" adaptation velocity $v_{\mathrm{SL}}$. However, because of contact line pinning, it is unclear whether the high contact line velocities after depinning are caused by adaptation, by slip, or by a combination of both. Therefore, we did not fit data from the receding curves. To check whether dynamic contact angles can also be described by conventional hydrodynamic (Cox-Voinov) and molecular kinetic (MKT) models, we fitted our data sets using both theories. As far as we know, hydrodynamic theory cannot account for the wetting-induced lubrication transition. For instance, fitting our data with the Cox-Voinov model results in invalid values as it is typically utilized for high capillary numbers (Supporting Information, Figure S7). ${ }^{4,5}$ We also tested our results against the molecular kinetic theory, ${ }^{38,39}$ yielding values under a comparatively poor fit for a friction coefficient of $74 \mu \mathrm{N} \mathrm{s} / \mathrm{mm}^{2}$. With an assumed hopping distance of $1 \mathrm{~nm}$, the hopping frequency is $55 \mathrm{kHz}$ (Supporting Information, Figure S8). An alternative recently proposed by Perrin et al. described a unified model including both hydrodynamics and thermal activation over defects. $^{40,41}$ The main difference between adaptive wetting and the approach in Perrin et al. lies in the understanding of defects. Perrin et al. assume that the defects do not change in course of the experiment and can be characterized by their height, width, distance, and strength. ${ }^{40}$ These parameters do not change because of the presence or absence of water. In contrast, adaptive wetting assumes that the substrate can change because of contact with the drop. ${ }^{12}$ This implies that the presence of the sessile drop changes the height, width, distance, and strength of a defect. Perrin's model was fitted over four parameters and provided the fit parameters of a transitional capillary number of $1.7 \times 10^{-6}$, a defect spacing of $1 \mathrm{~nm}$, and a static contact angle of $125^{\circ}$ (Supporting Information, Figure S9). So far, these models are unable to provide reasonable results (physical realism) for describing wetting-induced lubrication.

\section{CONCLUSIONS}

To describe the wetting of pristine PDMS by water, one needs to consider that the surface adapts. Dynamic advancing contact angles depend on velocity of the contact line. Receding contact angles depend on the time the surface had been in contact with water. For PDMS, results indicate that adaptation of the solid-liquid interface is caused by trapped oligomers in the polymer matrix that were pulled out from the PDMS matrix. The oligomers induce a reversible transformation from the dry to the lubricated wetting state. After the drop is removed, the oligomers slowly (several minutes) diffuse back into the bulk phase. This long residence time of oligomers would also explain why previous experiments were often difficult to interpret: measured contact angles depend on the history of a sample. This scenario should be generic, that is, holds for all surfaces containing mobile molecules or containing dangling ends, particularly for soft polymeric solids. The presence of oligomers at the interface results in the formation of a PDMS surface with a net lower surface tension. Wetting adaptation may thus unveil previously unknown contributions to changes in dynamic contact angles and contact line hysteresis on chemically and topologically homogeneous ideal surfaces. 


\section{ASSOCIATED CONTENT}

\section{(s) Supporting Information}

The Supporting Information is available free of charge at https://pubs.acs.org/doi/10.1021/acs.langmuir.0c00538.

Gel-permeation chromatography elution spectra; contact angle and contact line velocity plots at low- $(50 \mathrm{~nL} / \mathrm{s})$ and high- $(1000 \mathrm{~nL} / \mathrm{s})$ contact line velocities for controls; confocal microscopy at the water-on-pristine PDMS contact line; contact angle and contact line velocity plots at low contact line velocities; contact angle and contact line velocity plots at high contact line velocities; mechanism of drop depinning during the receding halfcycle; Cox-Voinov fit using hydrodynamics theory; fit of the molecular kinetic theory; and fit based on unified hydrodynamics and thermal activation-based model (PDF)

Characteristic advancing-receding contact angle cycle at $50 \mathrm{~nL} / \mathrm{s}$ (AVI)

Characteristic advancing-receding contact angle cycle at $1000 \mathrm{~nL} / \mathrm{s}$ (AVI)

\section{AUTHOR INFORMATION}

Corresponding Author

Hans-Jürgen Butt - Max Planck Institute for Polymer Research, D-55128 Mainz, Germany; 이이.org/0000-0001-53912618; Email: butt@mpip-mainz.mpg.de

\section{Authors}

William S. Y. Wong - Max Planck Institute for Polymer Research, D-55128 Mainz, Germany; (i) orcid.org/0000-0002-53895018

Lukas Hauer - Max Planck Institute for Polymer Research, D55128 Mainz, Germany

Abhinav Naga - Max Planck Institute for Polymer Research, D55128 Mainz, Germany

Anke Kaltbeitzel - Max Planck Institute for Polymer Research, D-55128 Mainz, Germany

Philipp Baumli - Max Planck Institute for Polymer Research, D55128 Mainz, Germany

Rüdiger Berger - Max Planck Institute for Polymer Research, D55128 Mainz, Germany; 이이.org/0000-0002-4084-0675

Maria D‘Acunzi - Max Planck Institute for Polymer Research, D55128 Mainz, Germany

Doris Vollmer - Max Planck Institute for Polymer Research, D55128 Mainz, Germany; @ orcid.org/0000-0001-9599-5589

Complete contact information is available at:

https://pubs.acs.org/10.1021/acs.langmuir.0c00538

\section{Author Contributions}

W.S.Y.W. and M.D. fabricated the surfaces. W.S.Y.W. carried out the experiments and characterization unless otherwise stated. L.H. and W.S.Y.W. analyzed the system analytically to understand the phenomenon. A.N. and A.K. supported experiments on surface tension measurements and confocal microscopy. P.B. and R.B. discussed and improved our understanding behind ultra-thin PDMS controls (brushes) and supplementary atomic force microscopy measurements, respectively. W.S.Y.W., L.H., D.V., and H.-J.B. contributed to experimental planning, data analysis, and manuscript preparation. All authors reviewed and approved the manuscript.

\section{Notes}

The authors declare no competing financial interest.

\section{ACKNOWLEDGMENTS}

This work was supported by the European Union's Horizon 2020 research and innovation program LubISS no. 722497 (W.S.Y.W., A.N., P.B., and D.V.), and the German Research Foundation (DFG, SPP2171: D.V., L.H., R.B., and H.-J.B.). We thank A. Sharifi for technical support and F. Geyer, K. Hegner, D. Diaz, H. Teisala, A. Saal, A. Stetten, and especially S. Silge for stimulating discussions.

\section{REFERENCES}

(1) Barrie, J. A.; Machin, D. The Sorption and Diffusion of Water in Silicone Rubbers. Part Ii. Filled Rubbers. J. Macromol. Sci., Part B: Phys. 1969, 3, 673-692.

(2) Watson, J. M.; Baron, M. G. The Behaviour of Water in Poly(Dimethylsiloxane). J. Membr. Sci. 1996, 110, 47-57.

(3) Blake, T. D. The Physics of Moving Wetting Lines. J. Colloid Interface Sci. 2006, 299, 1-13.

(4) Snoeijer, J. H.; Andreotti, B. Moving Contact Lines: Scales, Regimes, and Dynamical Transitions. Annu. Rev. Fluid. Mech. 2013, 45, 269-292.

(5) Voinov, O. V. Hydrodynamics of Wetting. Fluid Dyn. 1976, 11, 714-721.

(6) Blake, T. D. Forced Wetting of a Reactive Surface. Adv. Colloid Interface Sci. 2012, 179-182, 22-28.

(7) Blake, T. D.; De Coninck, J. Dynamics of Wetting and Kramers' Theory. Eur. Phys. J.: Spec. Top. 2011, 197, 249.

(8) Le Grand, N.; Daerr, A.; Limat, L. Shape and Motion of Drops Sliding Down an Inclined Plane. J. Fluid Mech. 2005, 541, 293-315.

(9) Henrich, F.; Fell, D.; Truszkowska, D.; Weirich, M.; Anyfantakis, M.; Nguyen, T.-H.; Wagner, M.; Auernhammer, G. K.; Butt, H.-J. Influence of Surfactants in Forced Dynamic Dewetting. Soft Matter 2016, 12, 7782-7791.

(10) Petrov, J. G.; Ralston, J.; Schneemilch, M.; Hayes, R. A. Dynamics of Partial Wetting and Dewetting in Well-Defined Systems. J. Phys. Chem. B 2003, 107, 1634-1645.

(11) Ralston, J.; Popescu, M.; Sedev, R. Dynamics of Wetting from an Experimental Point of View. Annu. Rev. Mater. Res. 2008, 38, 23-43.

(12) Butt, H.-J.; Berger, R.; Steffen, W.; Vollmer, D.; Weber, S. A. L. Adaptive Wetting-Adaptation in Wetting. Langmuir 2018, 34, 1129211304.

(13) Gubanski, S. M.; Vlastos, A. E. Wettability of Naturally Aged Silicon and Epdm Composite Insulators. IEEE Trans. Power Delivery 1990, 5, 1527-1535.

(14) Morra, M.; Occhiello, E.; Marola, R.; Garbassi, F.; Humphrey, P.; Johnson, D. On the Aging of Oxygen Plasma-Treated Polydimethylsiloxane Surfaces. J. Colloid Interface Sci. 1990, 137, 11-24.

(15) Kim, J.; Chaudhury, M. K.; Owen, M. J. Modeling Hydrophobic Recovery of Electrically Discharged Polydimethylsiloxane Elastomers. J. Colloid Interface Sci. 2006, 293, 364-375.

(16) Eddington, D. T.; Puccinelli, J. P.; Beebe, D. J. Thermal Aging and Reduced Hydrophobic Recovery of Polydimethylsiloxane. Sens. Actuators, B 2006, 114, 170-172.

(17) Collins, A. M. Physical Techniques. In Nanotechnology Cookbook; Collins, A. M., Ed.; Elsevier: Oxford, 2012; Chapter 5, pp 205-253.

(18) Korhonen, J. T.; Huhtamäki, T.; Ikkala, O.; Ras, R. H. A. Reliable Measurement of the Receding Contact Angle. Langmuir 2013, 29, $3858-3863$.

(19) Srinivasan, S.; McKinley, G. H.; Cohen, R. E. Assessing the Accuracy of Contact Angle Measurements for Sessile Drops on LiquidRepellent Surfaces. Langmuir 2011, 27, 13582-13589.

(20) Saad, S. M. I.; Neumann, A. W. Axisymmetric Drop Shape Analysis (Adsa): An Outline. Adv. Colloid Interface Sci. 2016, 238, 6287.

(21) Xu, Z. N.; Wang, S. Y. A Highly Accurate Dynamic Contact Angle Algorithm for Drops on Inclined Surface Based on Ellipse-Fitting. Rev. Sci. Instrum. 2015, 86, 025104. 
(22) Wong, W. S. Y.; Tricoli, A. Cassie-Levitated Droplets for Distortion-Free Low-Energy Solid-Liquid Interactions. ACS Appl. Mater. Interfaces 2018, 10, 13999-14007.

(23) Wang, L.; McCarthy, T. J. Covalently Attached Liquids: Instant Omniphobic Surfaces with Unprecedented Repellency. Angew. Chem., Int. Ed. 2016, 55, 244-248.

(24) Wong, T.-S.; Kang, S. H.; Tang, S. K. Y.; Smythe, E. J.; Hatton, B. D.; Grinthal, A.; Aizenberg, J. Bioinspired Self-Repairing Slippery Surfaces with Pressure-Stable Omniphobicity. Nature 2011, 477, 443447.

(25) Pham, J. T.; Schellenberger, F.; Kappl, M.; Butt, H.-J. From Elasticity to Capillarity in Soft Materials Indentation. Phys. Rev. Mater. 2017, 1, 015602.

(26) Whitesides, G. M. The Origins and the Future of Microfluidics. Nature 2006, 442, 368-373.

(27) van Gorcum, M.; Andreotti, B.; Snoeijer, J. H.; Karpitschka, S. Dynamic Solid Surface Tension Causes Droplet Pinning and Depinning. Phys. Rev. Lett. 2018, 121, 208003.

(28) Johnston, I. D.; McCluskey, D. K.; Tan, C. K. L.; Tracey, M. C. Mechanical Characterization of Bulk Sylgard 184 for Microfluidics and Microengineering. J. Micromech. Microeng. 2014, 24, 035017.

(29) Lafuma, A.; Quéré, D. Slippery Pre-Suffused Surfaces. Europhys. Lett. 2011, 96, 56001.

(30) Smith, J. D.; Dhiman, R.; Anand, S.; Reza-Garduno, E.; Cohen, R. E.; McKinley, G. H.; Varanasi, K. K. Droplet Mobility on LubricantImpregnated Surfaces. Soft Matter 2013, 9, 1772-1780.

(31) Pericet-Cámara, R.; Best, A.; Butt, H.-J.; Bonaccurso, E. Effect of Capillary Pressure and Surface Tension on the Deformation of Elastic Surfaces by Sessile Liquid Microdrops: An Experimental Investigation. Langmuir 2008, 24, 10565-10568.

(32) Fernandez-Toledano, J.-C.; Blake, T. D.; Lambert, P.; De Coninck, J. On the Cohesion of Fluids and Their Adhesion to Solids: Young's Equation at the Atomic Scale. Adv. Colloid Interface Sci. 2017, 245, 102-107.

(33) Butt, H.-J.; Semprebon, C.; Papadopoulos, P.; Vollmer, D.; Brinkmann, M.; Ciccotti, M. Design Principles for Superamphiphobic Surfaces. Soft Matter 2013, 9, 418-428.

(34) Jalbert, C.; Koberstein, J. T.; Yilgor, I.; Gallagher, P.; Krukonis, V. Molecular Weight Dependence and End-Group Effects on the Surface Tension of Poly(Dimethylsiloxane). Macromolecules 1993, 26, 30693074.

(35) Karpitschka, S.; Das, S.; van Gorcum, M.; Perrin, H.; Andreotti, B.; Snoeijer, J. H. Droplets Move over Viscoelastic Substrates by Surfing a Ridge. Nat. Commun. 2015, 6, 7891.

(36) Eggers, J. Existence of Receding and Advancing Contact Lines. Phys. Fluids 2005, 17, 082106.

(37) Hänni-Ciunel, K.; Findenegg, G.; Klitzing, R. Water Contact Angle on Polyelectrolyte-Coated Surfaces: Effects of Film Swelling and Droplet Evaporation. Soft Mater. 2007, 5, 61-73.

(38) Ray, S.; Sedev, R.; Priest, C.; Ralston, J. Influence of the Work of Adhesion on the Dynamic Wetting of Chemically Heterogeneous Surfaces. Langmuir 2008, 24, 13007-13012.

(39) Pilat, D. W.; Papadopoulos, P.; Schäffel, D.; Vollmer, D.; Berger, R.; Butt, H.-J. Dynamic Measurement of the Force Required to Move a Liquid Drop on a Solid Surface. Langmuir 2012, 28, 16812-16820.

(40) Perrin, H.; Lhermerout, R.; Davitt, K.; Rolley, E.; Andreotti, B. Thermally Activated Motion of a Contact Line over Defects. Soft Matter 2018, 14, 1581-1595.

(41) Perrin, H.; Lhermerout, R.; Davitt, K.; Rolley, E.; Andreotti, B. Defects at the Nanoscale Impact Contact Line Motion at All Scales. Phys. Rev. Lett. 2016, 116, 184502. 